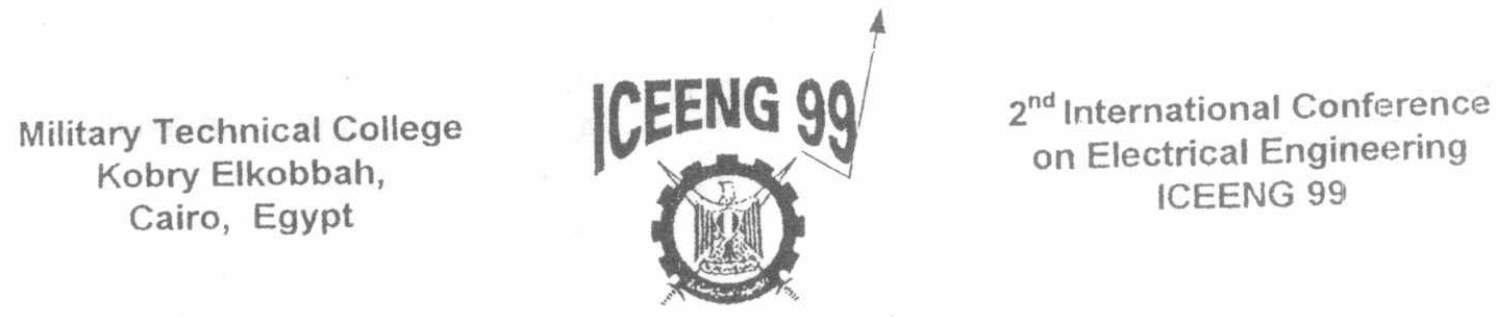

\title{
SYSTEMATIC DESIGN PROCEDURE OF SWITCHED RELUCTANCE MOTORS
}

\author{
Amged El-Wakeel*, Said A. Gawish**, M. A. L. Badr***
}

\begin{abstract}
While numerical analysis techniques, such as a finite element analysis and boundary element analysis, have been presented as an accurate tool for design and simulation of Switched Reluctance Motors, they do not give any method of a systematic design procedure with a minimum computational effort. Besides, They have not introduced any matching with the conventional design approaches used in classical machine design. This paper presents a systematic design procedure based on magnetic circuit analysis and standard proportion among motor parts to determine the motor dimensions. The proposed procedure is generally structured to run on personal computers to design and simulate any permissible specifications, in a few minutes. It has been shown that, for fast and more traditional design, no numerical techniques are needed, since the magnetic circuit analysis is more simple and complete in itself. The proposed program is not limited only to the motor iron and copper dimensions, but also estimates many of performance indices such as output power density, generalized power factor, losses and efficiency.
\end{abstract}

\section{KEYWORDS}

Switched Reluctance Motors, Design of Electrical Machines.

\section{NOMENCLATURE}

$\begin{array}{llll}a_{w} & \text { Wire cross sectional area. } & d_{s h} & \text { Shaft diameter. } \\ A R_{1} & \text { Stator pole aspect ratio. } & D & \text { Bore ( rotor outer) diameter. } \\ B_{s} & \text { Saturating flux density. } & D_{o} & \text { Outer motor diameter. } \\ C_{0}, C_{0}{ }^{\prime} & \begin{array}{l}\text { Normal and maximum Output } \\ \text { coefficients. }\end{array} & D_{r i} & \begin{array}{l}\text { Internal diameter of the } \\ \text { rotor. }\end{array} \\ d_{s} & \text { Stator slot depth. } & D_{s} & \text { Stator airgap diameter. }\end{array}$

*** Professor, Dept. Of Elect. Power \& Machines, Faculty of engineering, Ain Shams University, Cairo, Egypt. ${ }^{* *}$ Associate professor, Dept. Of Elect. Power \& Energy, Egyptian Armed Forces. * M. Sc. , Dept. Of Elect. Power \& Energy, Egyptian Armed Forces. 
Proceedings of the $2^{\text {nd }}$ ICEENG Conference, 23-25 Nov. 1999.

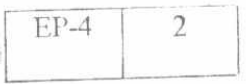

\begin{tabular}{|c|c|c|c|}
\hline si & Internal stator diameter. & $s r$ & Split ratio. \\
\hline E & Motional electromotive force. & $t_{r}, t_{s}$ & Rotor and stator pole widihs. \\
\hline & Pole geometry function. & $\begin{array}{l}T_{a} \\
T_{a}^{\prime}\end{array}$ & $\begin{array}{l}\text { Average and maximum } \\
\text { average torque. }\end{array}$ \\
\hline$F_{2}$ & $\begin{array}{l}\text { Minimum and maximum } \\
\text { magneto-motive forces. }\end{array}$ & V & Applied voltage. \\
\hline$p, h_{s p}$ & Rotor and stator pole heights. & $\begin{array}{l}W_{s t} \\
W_{s b}\end{array}$ & $\begin{array}{l}\text { Top and bottom Slot widths of } \\
\text { the stator. }\end{array}$ \\
\hline , Ir.m.s & $\begin{array}{l}\text { Maximum and effective phase } \\
\text { currents. }\end{array}$ & $W$ & $\begin{array}{l}\text { Maximum change of the } \\
\text { coenergy. }\end{array}$ \\
\hline 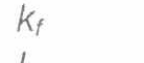 & Slot filling factor & $\alpha$ & Stator pole arc. \\
\hline & Airgap length. & $\beta, \beta$ & Rotor pole and interpolar arcs. \\
\hline$L_{e}$ & Stack and envelope lengths. & $\delta$ & Effective current density. \\
\hline$-\max$ & $\begin{array}{l}\text { Maximum and minimum linear } \\
\text { self inductance. }\end{array}$ & $\theta_{s}$ & $\begin{array}{l}\text { The mechanical angle of the } \\
\text { stator pole pitch. }\end{array}$ \\
\hline & Number of stator poles. & $\lambda_{\max }$ & $\begin{array}{l}\text { The maximum aligned flux } \\
\text { linkage. }\end{array}$ \\
\hline$n$ & Number of rotor poles. & $\lambda_{\min }$ & $\begin{array}{l}\text { The minimum unaligned flux } \\
\text { linkage. }\end{array}$ \\
\hline$N_{P H}$ & Number of turns per phase. & $\rho_{1}, \rho_{2}$ & $\begin{array}{l}\text { Linear gap permeance } \\
\text { functions. }\end{array}$ \\
\hline$P^{\prime}$ & $\begin{array}{l}\text { Average and } \\
\text { average poweres. }\end{array}$ & $\tau_{r}, \tau_{s}$ & Rotor and stator pole pitches. \\
\hline
\end{tabular}

\section{INTRODUCTION}

Although SRMs are simple in construction they are difficult in design and analysis. These difficulties are summarized mainly in strong spatial and magnetic nonlinearities with many flexible design parameters, and interdependence on the design of the converter and control parameters. These difficulties and others accompanied with iron losses and thermal rating prediction make the design procedure of the motor difficult and specialized task.

A variety of publications on the design of SRMs are available and provide a wealthy information regarding the design and construction of SR motors [1:10]. Some of these publications introduce general design considerations and some design equations [1:8] and others demonstrate the applications of computer aided design packages $[9,10]$.

The numerical analysis techniques and integrated design methodology, for SRM have been presented in many publications $[11,12]$. It has been shown that, for quick and more traditional design, no numerical techniques are required, since the lumped parameter analysis is complete in itself $[12,13]$. However, for more accurate calculations, numerical techniques can be used to confirm and improve the results of the analytical design work [13].

This paper differs from the previous papers, in the following aspects:

it presents a systematic routine for the complete motor dimension prediction; 
Proceedings of the $2^{\text {nd }}$ ICEENG Conference, 23-25 Nov. 1999.

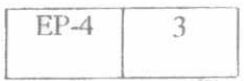

it requires only one human to computer operation until the solution is found and hence minimum time of execution.

the proposed program is written in Matlab and is generally structured to run on personal computers to design and simulate any permissible specifications, in a few minutes.

\section{DESIGN APPROACH}

In this paper, the design is an iterative procedure based on magnetic circuit analysis with approximate flux path calculations which provides fast design of many of the SRM dimensions. Also the design is based on the use of standard proportions and graphical relation among motor parts to determine the rest of dimensions. The static and dynamic simulations of the SRM are included as an integral part of the design procedure in order țo predict the motor performance and make design verification.

\subsection{Design Limitations}

Fig. (1) shows the construction and main dimensions of SRM, and it is clear that a successful design brings out a compromise for space occupied by iron, copper, insulation and air. Actually, the designer must face the general design limitations in choosing the suitable amount and type of materials for the fabrication of the required machine parts. These limitations include the consumer requirements, the saturation level, the allowed temperature rise, the value of power factor, the efficiency and the mechanical design limitations.

The most basic consumer requirements are the output power $P_{r}$, the base speed $n_{r}$ and the supply voltage $V$. Temperature rise, envelope dimensions, overload rating, level of protection and maximum noise level are examples of requirements and constraints that may be required [14].

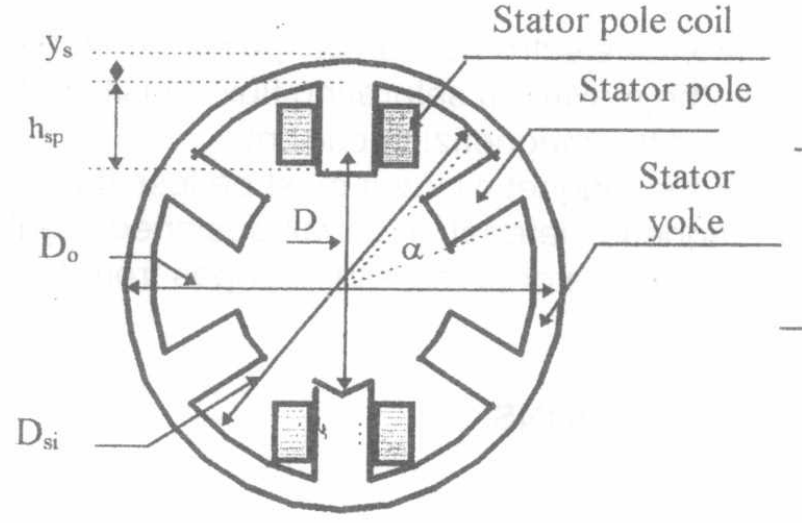

(a)

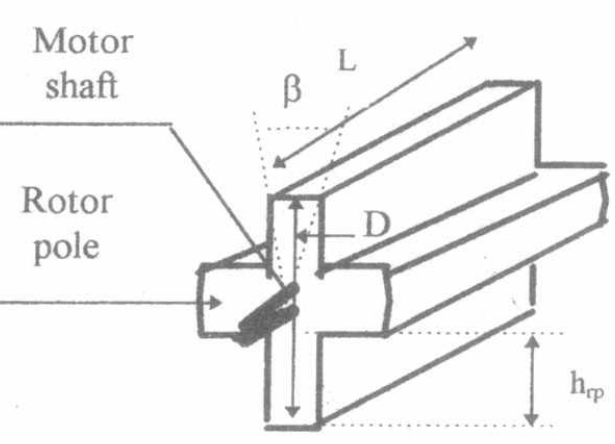

(b)

Fig. 1: Motor construction.

(a) Stator dimensions.

(b) Rotor dimensions. 


\subsection{Design Parameters}

Some parameters such as, the number of phases $q$, number of stator poles $m$, number of rotor poles $n$, lamination stacking factor $k_{\text {st }}$ and conductor resistivity $\rho$ with its temperature coefficient are usually chosen by the designer and assumed as fixed parameters. Other quasi-fixed parameters like, effective current density $\delta$, saturating flux density $B_{s}$ are assumed constants with the permeability of minor changes in the iterative design method.

Many parameters such as the outer stator diameter $D_{o}$, and airgap length $I_{g}$, the stator and rotor pole widths $t_{s}, t_{r}$, and the stator and rotor yoke widths $y_{s}, y_{r}$ e.t.c. can be computed from the fixed and quasi-fixed parameters geometrically or by 'ratioing' from the main dimensions, starting from 'standard' proportions.

\subsubsection{Choice of Parameters}

\section{(i) Choice of the number of phases}

From fault tolerance point of view, the fault tolerant motor must be a polyphase motor, and hence all single phase motors are rejected, and from reversible self starting point of view all single and two phase motors are rejected [15]

P. J. Lawrenson [1] explained that, from efficiency point of view, the number of phases must be kept as low as possible to decrease the switching frequency and hence decrease the iron losses. However, if a low speed application is being considered, the limitation imposed by frequency will be less effective and the designer has greater freedom in choice. In practice, the majority of motors have three or four phases, and it is rare to find motors with more than five phases.

(ii) Choice of number of stator and rotor poles

The number of stator poles and rotor poles can be obtained as:

$$
\begin{aligned}
& m=k q \\
& n=m-k
\end{aligned}
$$

Where $k$ is an evert number. It has been noted that in order to decrease the iron losses and increase the efficiency, the number of poles must be minimum especially in high speed applications, therefore $k$ is usually taken as 2 to decrease the number of stator poles and hence decrease the number of rotor poles [ 1,5 ].

(iii) Choice of magnetic loading

The magnetic flux density $B$ is relevant to the electromechanical power conversion process and basically, it is determined by, the maximum saturating flux density in the iron parts of the machine, the iron losses and the magnetizing current.

The maximum flux density in any part of the magnetic circuit must be less than the limiting saturation value of the used magnetic material. In a well-designed regular SRMs the maximum flux density occurs in the stator poles and it ranges from 1.8 to 2.5 Tesla depending

\section{THE OUTPUT EQUATION AND MAIN DIMENSIONS}

\subsection{Output Equation}

The output of a machine can be related to its main dimensions and speed as :

$$
P=C_{0} D^{2} L n_{r}
$$

Where $C_{0}$ is the output coefficient, $D$ is the outer rotor diameter, $L$ is rotor axial length and $n_{r}$ is the base speed. 
Proceedings of the $2^{\text {nd }}$ ICEENG Conference, 23-25 Nov. 1999.

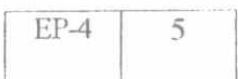

References [10] and [16] explained that, it is easy to determine $C_{0}$ for an existing motor whose power, speed and rotor dimensions are known. For similar cooling, this value is often a convenient starting point for a new design of the same torque, even when the new motor is SRM and the old is conventional.

In this section, The value of $C_{0}$ will be derived based on the unified approach of static torque production in saturated doubly salient machines $[17,18]$. As shown in Fig 2 , the maximum value of the change in coenergy $W^{\prime}$ (shaded area), as the magneto-motive force $F$ tends to infinity, is equal to the triangular area obc. This yields to:

$$
W=\frac{\phi_{1}^{2}}{2 \mu_{o} L}\left[\frac{1}{\rho_{1}}-\frac{1}{\rho_{2}}\right]
$$

Where, $\rho_{1}$ and $\rho_{2}$ are the linear gap permeance functions in aligned and unaligned positions and the saturation ultimately limits the stator pole flux $\phi$ to a value $\phi_{1}$. The average torque $T_{a}$ can be expressed as [10]:

$$
T_{a}=\frac{q \cdot n}{2 \pi} W
$$

From equations (1) and (4) into equation (5) the maximum average torque $T_{a}^{\prime}$ can be expressed as:

$$
T_{a}^{\prime}=\frac{m \cdot n}{4 \pi} \cdot \frac{\phi_{1}^{2}}{2 \mu_{o} L} \cdot\left[\frac{1}{\rho_{1}}-\frac{1}{\rho_{2}}\right]
$$

The ultimate stator pole flux $\phi_{1}$ can be expressed as:

$$
\phi_{1}=B_{s} t_{s} L k_{s t}
$$

Where $B_{s}$ is the peak flux density set by the saturation limit of the stator pole, $t_{s}$ is the stator pole width and $k_{s t}$ is the stacking factor. It is easy seen that the maximum value of the average torque

$$
T_{a}^{\prime}=\frac{\pi \cdot D^{2} L k_{S T}}{4}\left[\frac{B_{s}^{2}}{2 \cdot \mu_{s}}\right] \cdot\left[\frac{t_{s}^{2}}{\tau_{r} \cdot \tau_{s}}\right]\left[\frac{1}{\rho_{1}}-\frac{1}{\rho_{2}}\right]
$$

From the previous equation, the maximum average power in $\mathrm{KW}$ can be expressed as:

$$
P^{\prime}=\frac{\pi^{2} 10^{-3}}{240 \cdot \mu_{o}} k_{S T} B_{s}^{2} \cdot f_{1}^{\prime} \cdot D^{2} L n_{r}
$$

Where $f_{1}{ }^{\prime}$ is the maximum value of the gap geometry function $f_{1}$ which is given by:

$$
f_{1}=\left[\frac{t_{s}^{2}}{\tau_{r} \cdot \tau_{s}}\right] \cdot\left[\frac{1}{\rho_{1}}-\frac{1}{\rho_{2}}\right]
$$

The maximum value of $f_{1}$ is about 0.025 which may be used to give a guide to the limiting value of output coefficient predicted by non-linear theory. The result, from equation (10) is:

$$
C_{o}{ }^{\prime}=\frac{\pi}{4} B_{s}^{2}
$$

Where $C_{o}{ }^{\prime}$ ranges from 2.5 to 5 for $B_{s}$ ranging from 1.75 to 2.5 Tesla. In an actual machine, the real value of $C_{o}$ depends on the gap geometry, the saturation level, and the motor mechanical losses. So these effects can be expressed as the correction factor $C_{f}$ multiplied by the value of $C_{o}^{\prime}$. 
Proceedings of the $2^{\text {nd }}$ ICEENG Conference, 23-25 Nov. 1999.

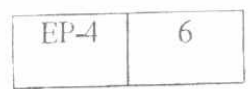

$$
C_{o}=C_{f} \frac{\pi}{4} B_{s}^{2}
$$

The value of $C_{f}$ ranges from less than 0.25 for unsaturated small machines and 0.7 for medium saturated machines to 0.98 for high saturated machines with optimum gap geometry which will be explained later.

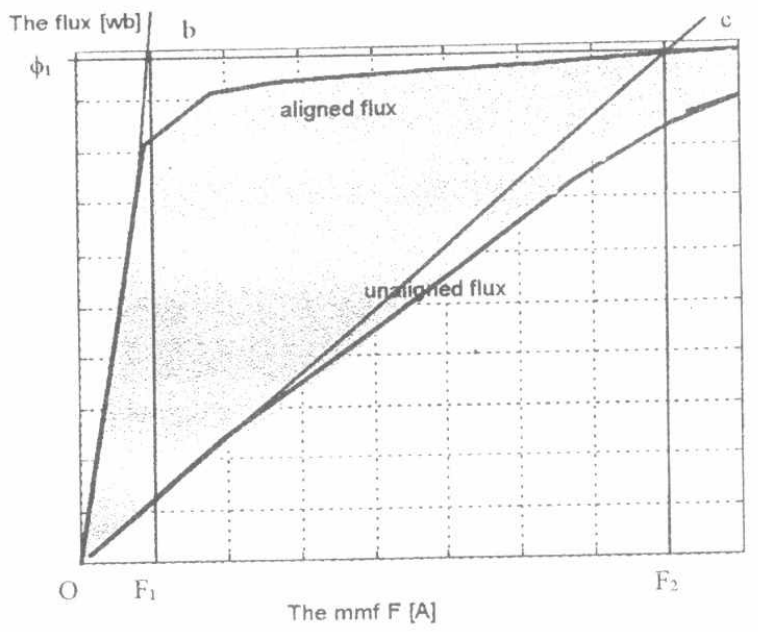

Fig. 2: Stator pole flux against excitation $\mathrm{mmf}(\mathrm{F})$.

\subsection{Separation of $D$ and $L$}

The factors which influence the relative values of $D$ and $L$ are different for different types of electric machines. For SRM these factors are:

\section{(i) The stator pole proportions}

The ratio of core leagth $L$ to the stator pole pitch $\tau_{s}$ determines the weight of the copper and hence the economics of the machine. This ratio is usually called the stator aspect ratio $A R_{1}$ and usually ranges from 1 to 6 for practical SRMs. From this ratio the value of $L / D$ can be computed as:

$$
\frac{l}{l)}=A R_{1} \frac{\pi}{m}
$$

For $A R_{1}$ ranging from 1 to 6 and $m$ ranging from 6 to 12 , the value of $L D$ ranges from about 0.3 to 3 .

\section{(ii) Peripheral speed}

Usually, the rotor critical speed imposes a limit on the rotor diameter $D$ [10], because if the rotor peripheral speed $V_{p}$ is increased, the rotor may be destroyed due to increased centrifugal force.

The peripheral speed may be greater than $175 \mathrm{~m} / \mathrm{s}$ for high speed SRMs incorporating amorphous iron [17]. However, the peripheral speed usually does not exceed $60 \mathrm{~m} / \mathrm{s}$ for most normal SRMs.

(iii) Number of poles.

It is advisable to increase the diameter of the machine which has large number of poles. This may be done to obtain sufficient room for the stator coils. 
Proceedings of the $2^{\text {nd }}$ ICEENG Conference, 23-25 Nov. 1999.

\begin{tabular}{|l|l|}
\hline $\mathrm{EP}-4$ & 7 \\
\hline
\end{tabular}

\section{STATOR DESIGN EQUATIONS}

The stator dimensions include the envelope dimensions, the internal and airgap stator radii and the slot and tooth dimensions. Many of these dimensions can be seen in Fig. 1.a.

\subsection{Airgap length and Airgap Stator Diameter}

H. C. J. De Jong [20] explained that in the electric machines whose operation is based on permeance fluctuations, the airgap should be as small as mechanically acceptable for obtaining the best electromagnetic performance.

Thus, to maximize the specific torque and minimize the volt-ampere requirements in the controller the, airgap length will depend on the mechanical influence only and may be taken as:

$$
I_{g}=10^{-3} \frac{D}{2} \quad[\mathrm{~mm}]
$$

Where, $D$ is the bore diameter measured in [mm]. This relation is restricted with a minimum value of $0.2 \mathrm{~mm}$.

Larger airgap length may be required with special types of bearings, which depend on the machine length. The airgap may be increased to decrease the unbalance magnetic pull, which arises from any small deflection or eccentricity of the rotor shaft.

The following relation may be proposed based on the relation of the airgap length of induction motors and may also be usefully used in SRMs:

$$
I_{g}=0.2+10^{-3} \cdot D
$$

The value of $I_{g}$ usually exists between the two values computed by equations (14) and (15).

The airgap stator diameter $D_{s}$ can be determined from the motor geometry as:

$$
D_{s}=D+2 I_{g}
$$

\subsection{Envelope Dimensions}

The envelope volume may be one of the consumer requirements and in this case the designer must satisfy this restriction in his design.

When the envelope dimensions are not specified, it is easy to estimate them by standard scaling from the main dimensions.

The simplest way to estimate the outer stator diameter $D_{0}$ is from a typical or standard split ratio $\mathrm{sr}$ as:

$$
D_{0}=\frac{D_{s}}{s r}
$$

The value of $s r$ may vary over quite a wide range among 0.4 to 0.7 , with most designs around 0.5 to 0.57 depending on the number of stator and rotor poles, and on the operating requirements [14]. 
The envelope length $L_{e}$ may be estimated as the stack length plus two end turn overhangs. The overhang length can be approximated as 0.25 of the stator pole pitch, thus, the envelope length can be expressed as:

$$
L_{e} \cong L+\frac{\tau_{s}}{2}
$$

\subsection{STATOR TOOTH AND SLOT DIMENSIONS}

\subsubsection{Tooth Dimensions}

Both the stator pole arc $\alpha$ and the corresponding tooth width $t_{\mathrm{s}}$ require careful selection to satisfy the following conditions:

(i) The stator pole arc must be greater or equal to the step angle to ensure adequate overlap between phases and hence ensure self starting at all rotor positions.

(ii) The stator pole arc must be less than the rotor interpolar arc $\beta^{\prime}$ to ensure angular clearance between the stator and rotor pole corners and hence ensure sufficiently low unaligned inductance $L_{u}[1,14]$. From above conditions $\alpha$ can be expressed as

$$
\alpha_{s} \leq \alpha \leq \beta^{l}
$$

Where $\beta^{t}$ is the rotor interpolar arc and $\beta$ is the rotor pole arc. Once the stator pole arc has been chosen, the stator pole width can be determined as:

$$
t_{s}=\pi D_{s} \frac{\alpha}{360}
$$

The optimum range for the stator pole arc per stator pole pitch changes according to the objective function. However, in order to optimize the motor performance generally the optimum value can be taken among 0.33 and 0.42 [8].

Stator yoke width $y_{s}$ is a magnetic relational parameter. So, it can be determined by the solution of the magnetic circuit. The stator pole flux splits equally in both the stator and rotor back irons. Thus the back iron width must support one half of the stator pole flux. If the maximum flux density allowed in the back iron is $B_{\max }$, then the back iron width can be computed as:

$$
y_{s}=\frac{\phi_{S}}{2 B_{\max } k_{s t} L},
$$

The stator yoke represents the longest path for the magnetic flux, and therefore to decrease saturation and hence decrease the iron losses, we will take the stator back width as 0.55 to 0.75 of the stator pole width $t_{s}[5,8,14]$.

The stator pole height $h_{s p}$ can be computed as:

$$
h_{s p}=0.5\left(D_{s i}-D_{s}\right)
$$

Where $D_{s i}$ is the internal stator diameter, $D_{0}$ is the outer stator diameter and $D_{s}$ is the airgap stator diameter. This value is exactly true for the trapezoidal pole with a rectangular slot shape. 
Proceedings of the $\mathbf{2}^{\text {nd }}$ ICEENG Conference, 23-25 Nov. 1999.

\begin{tabular}{|l|l|}
\hline $\mathrm{EP}-4$ & 9 \\
\hline
\end{tabular}

\subsubsection{Slot Dimensions}

The slot dimensions are geometrical parameters so they can be computed from the basic stator dimensions. First, the slot depth $d_{s}$ can be computed as a difference between the internal and airgap stator radii as:

$$
d_{s}=0.5\left(D_{s i}-D_{s}\right)
$$

Second, the slot width at the top of the pole $w_{s t}$, and the slot width at the bottom of the pole $w_{s b}$ can be computed as:

$$
\begin{aligned}
& w_{s t}=D_{s}\left(\frac{\theta_{s}-\alpha}{2}\right), \\
& w_{s b}=D_{s i}\left(\frac{\theta_{s}-\alpha}{2}\right),
\end{aligned}
$$

where, $\theta_{s}$ is the angular stator pole pitch in radians.

\section{ROTOR DESIGN EQUATIONS}

\subsection{Shaft Diameter}

For SRM, the weight of the salient structure armature is often less than that of the induction motor, and so, the shaft diameter may be taken as:

$$
d_{s h}=\left\{\begin{array}{ll}
\frac{25 . q}{4} \cdot \sqrt[3]{\frac{P}{n_{r}}} & \text { for } q \leq 4 \\
25 \cdot \sqrt[3]{\frac{P}{n_{r}}} & \text { for } q \geq 5
\end{array} \mathrm{~cm}\right.
$$

Although, for high power and high speed applications, the shaft diameter can be taken as that of induction motor.

\subsection{Rotor Pole and Yoke Dimensions}

The rotor pole arc $\beta$ and the corresponding tooth width $t_{r}$ require careful selection to satisfy the following conditions:

(i) The rotor pole arc must be greater or equal to the step angle to ensure self starting of the motor at all rotor positions.

(ii) The rotor pole arc is preferred to be greater than the stator pole arc, this results in a region of constant inductance separating the positive and negative $\mathrm{d} L / \mathrm{d} \theta$ regions, which in turn provides additional time for the phase current to be completely turned off before the region of negative torque production, i.e.

$$
\beta \geq \alpha
$$

In terms of widths, $t_{r}$ should be greater than $t_{s}$ by about $2 \mathrm{I}_{\mathrm{g}}$ and the rotor pole width can be computed as:

$$
t_{r}=\pi D \frac{\beta}{360}
$$

The rotor yoke width $y_{r}$ is a magnetic relational parameter which is usually chosen to equalize flux densities in the rotor pole and the rotor yoke irons as:

$$
y_{r}=\frac{t_{r}}{2}
$$


Proceedings of the $2^{\text {nd }}$ ICEENG Conference, 23-25 Nov. 1999.

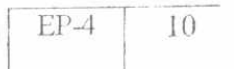

The lotor pole height $h_{r p}$ is a geometrical parameter which can be computed for the trapezoidal pole with a rectangular slot shape as:

$$
h_{r p}=0.5\left(D-D_{r i}\right)
$$

where, $D_{r i}$ is the internal rotor diameter.

\section{DESIGN OF STATOR WINDING}

In SRM, there are two types of coils:

(i) Dropped in coils, with a maximum slot filling factor of 0.4 .

(ii) Pushed through coils, in which the slot filling factor may be as low as 0.4 for small round conductors increasing to 0.75 for rectangular conductors.

\subsection{Number of Turns}

In this design approach, the design point is taken to produce the flat topped current waveform at minimum speed at which the full power is produced. According to this approach the back emf $E$ is equal to the dc bus voltage $V$, the back emf $E$ can be expressed as:

$$
E=\omega \frac{\lambda_{\max }-\lambda_{\min }}{\alpha},
$$

where $\lambda_{\max }$ is the maximum aligned flux linkage and $\lambda_{\min }$ is the minimum or the unaligned flux linkage for the peak phase current.

$$
\begin{aligned}
& \lambda_{\text {max }}=0.5 N_{P^{\prime} I I}\left(B_{S} \cdot k_{S T} \cdot L \cdot D \cdot \alpha\right) \\
& \lambda_{\text {min }}=k \lambda_{\text {max }}
\end{aligned}
$$

From equations (31), (32) and (33) the number of turns per phase can be estimated as:

$$
N_{P H}=\frac{60 \mathrm{~V}}{(1-k) \cdot K_{S T} \pi n D L B_{S}}
$$

The value of $k$ depends on the degree of saturation and ranges from less than 0.1 for small unsaturated machines to about 0.5 or more for heavy saturated machines.

\subsection{Conductor Area}

The conductor area can be computed as:

$$
a_{W}=\frac{I_{R . M . S}}{\delta} \text { \& }
$$

Where, $I_{\text {R.M.S }}$ is the effective current per phase and $\delta$ is the effective current density which ranges from 3 to 6 for totally enclosed natural cooling motors and from 7 to 10 for external self ventilation motors [14]

The effective phase current can be approximated as [6]:

$$
I_{\text {R.M.S }}=\frac{\operatorname{lm}}{\sqrt{q}}
$$


Proceedings of the $\mathbf{2}^{\text {nd }}$ ICEENG Conference, 23-25 Nov. 1999.

\begin{tabular}{|l|l|}
\hline $\mathrm{EP}-4$ & 11 \\
\hline
\end{tabular}

Where, $I m$ is the maximum flat current which can be computed from Ampere's circuital law at the aligned position. The total copper area per slot must satisfy a filling factor less or equal to the maximum filling factor.

\section{DESIGN PROCEDURE RESULTS}

In this section the proposed procedure is applied to design a small and fast motor. The main design dimensions and the motor characteristics for $1.1 \mathrm{KW}, 6 / 4$, 3-phase, 36 volt, 10000 r.p.m. SRM are summarized in the next table.

Table 1 Main dimensions and characteristics of $1.1 \mathrm{KW}, 6 / 4,3$-phase SRM

\begin{tabular}{|l|c|c|}
\hline \multicolumn{1}{|c|}{ Main Parameters } & design 1 & design 2 \\
\hline Rotor external diameter $(D)$ & $0.04 \mathrm{~m}$ & $0.043 \mathrm{~m}$ \\
\hline Axial length $(L)$ & $0.042 \mathrm{~m}$ & $0.034 \mathrm{~m}$ \\
\hline Internal rotor diameter $\left(D_{\text {ri }}\right)$ & $0.027 \mathrm{~m}$ & $0.028 \mathrm{~m}$ \\
\hline Airgap length $\left(I_{\mathrm{g}}\right)$ & $0.2 \mathrm{~mm}$ & $0.2 \mathrm{~mm}$ \\
\hline Stator diameter $\left(D_{\mathrm{s}}\right)$ & $0.0402 \mathrm{~m}$ & $0.044 \mathrm{~m}$ \\
\hline Stator internal diameter $\left(D_{\text {si }}\right)$ & $0.067 \mathrm{~m}$ & $0.067 \mathrm{~m}$ \\
\hline Outer diameter $\left(D_{\mathrm{o}}\right)$ & $0.08 \mathrm{~m}$ & $0.08 \mathrm{~m}$ \\
\hline Shaft diameter $\left(d_{\text {sh }}\right)$ & $0.008 \mathrm{~m}$ & $0.008 \mathrm{~m}$ \\
\hline Wire cross section area $\left(a_{\mathrm{w}}\right)$ & $3.464 \mathrm{~mm}$ & $3.464 \mathrm{~mm}^{2}$ \\
\hline Number of turns $\left(N_{\text {PH }}\right)$ & $34 \mathrm{turns}$ & $38 \mathrm{turns}$ \\
\hline Maximum flux density $B_{\mathrm{s}}$ & $1.874 \mathrm{Tesla}$ & $1.921 \mathrm{Tesla}$ \\
\hline Maximum phase inductance $\mathrm{L}_{\max }$ & $2.006 \mathrm{mH}$ & $2.226 \mathrm{mH}$ \\
\hline Minimum phase inductance $\mathrm{L}_{\min }$ & $0.181 \mathrm{mH}$ & $0.204 \mathrm{mH}$ \\
\hline Maximum phase current $I_{\mathrm{m}}$ & $59.154 \mathrm{~A}$ & $60.744 \mathrm{~A}$ \\
\hline Ideal Effective phase current $\mathrm{I}_{\text {eff }}$ & $34.133 \mathrm{~A}$ & $35.071 \mathrm{~A}$ \\
\hline Generalized power factor $(P F)$ & $0.613 \mathrm{lag}$ & $0.603 \mathrm{lag}$ \\
\hline Copper loss $\left(P_{\text {cu }}\right)$ & $0.103 \mathrm{KW}$ & $0.108 \mathrm{KW}$ \\
\hline Mechanical losses $\left(P_{\text {mech }}\right)$ & $0.011 \mathrm{KW}$ & $0.011 \mathrm{KW}$ \\
\hline Specific output power & $4214.55 \mathrm{KW} / \mathrm{m}^{3}$ & $4867.25 \mathrm{KW} / \mathrm{m}^{3}$ \\
\hline Motor full load efficiency $\eta \%$ & $84.26 \%$ & $83.47 \%$ \\
\hline
\end{tabular}

From the previous two tables, the increase in the specific output power and hence the decrease in the capital cost leads to a slightly decrease in the efficiency and slightly increase in the running cost. The decrease in efficiency in design 2 is due to the increase in the magnetic and electric loading and hence the increase in the iron and copper losses. The change in ideal dynamic torque curves, linear phase inductance, actual dynamic torque curves and flux linkage are clear from Figures 3 to Fig. 6. In Fig.4, the increase of maximum inductance in design 2 is due to the increase in the number of turns per phase. In Fig.5, negative torques existing in the actuai dynamic torque curves will not appear in the shaft and will be canceled with the positive torques of the other phase. 
Proceedings of the $2^{\text {nd }}$ ICEENG Conference, 23-25 Nov. 1999.

\begin{tabular}{|l|l|}
\hline $\mathrm{EP}-4$ & 12 \\
\hline
\end{tabular}

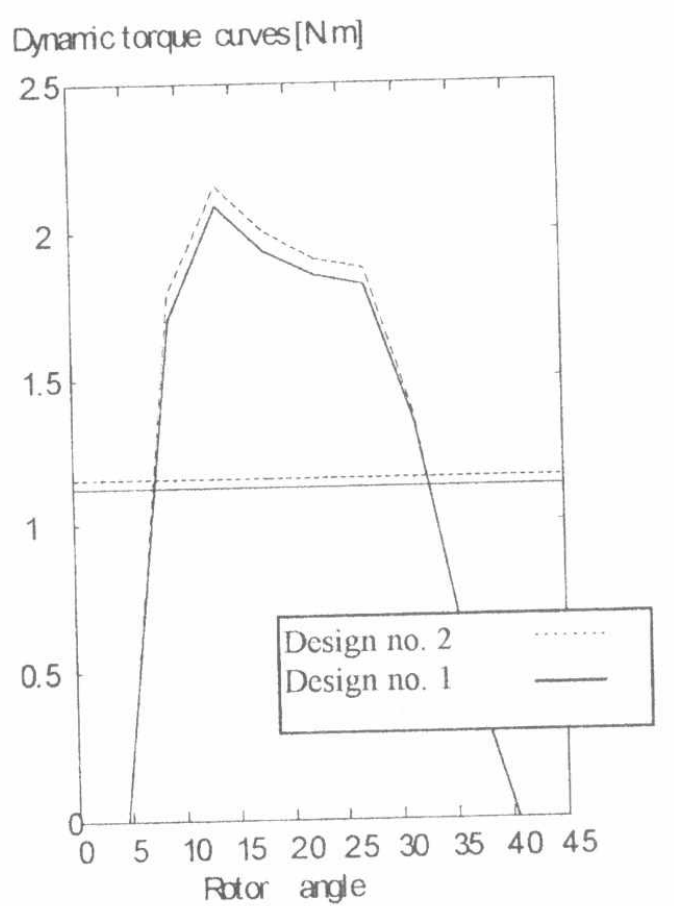

Fig. 3: Per-phase ideal dynamic and average torque curves.

Dynamic torques [ $\mathrm{Nm}$ ]

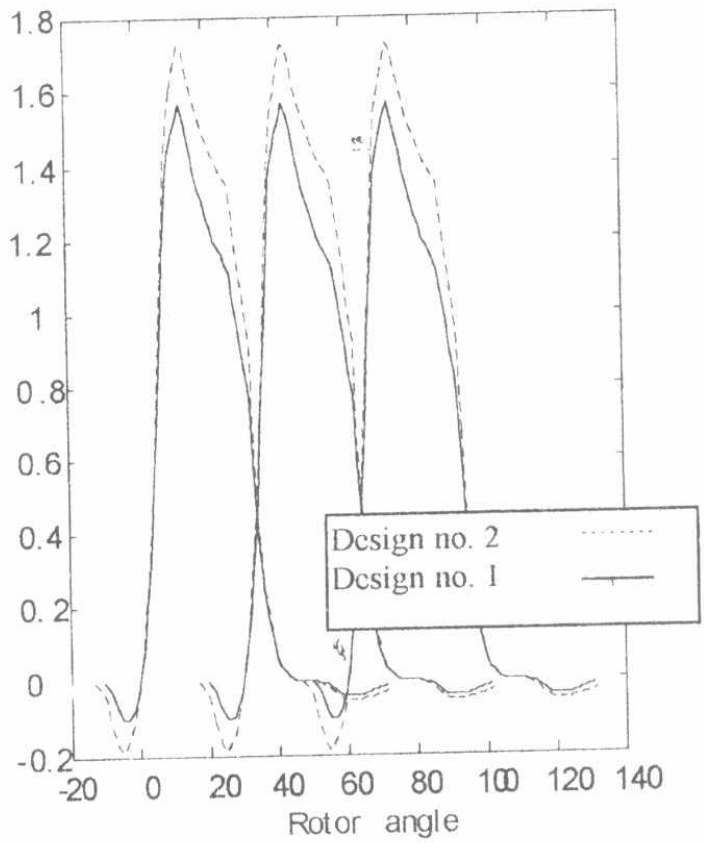

Fig. 5: Actual dynamic torque curves

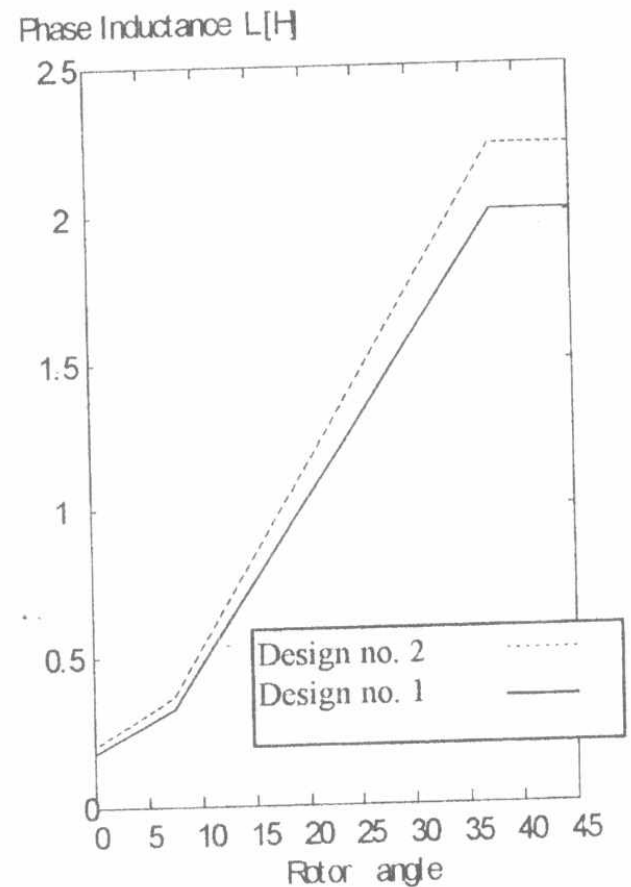

Fig.4: linear phase inductance.

flux linkage [wb]

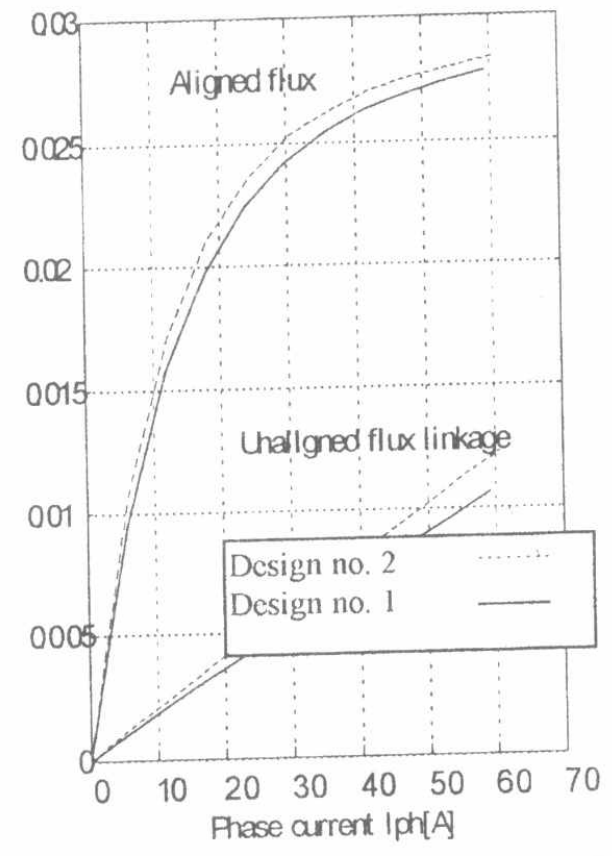

Fig. 6: Aligned and unaligned flux Linkage. 


\begin{tabular}{|l|l|}
\hline EP-4 & 13 \\
\hline
\end{tabular}

\section{CONCLUSION}

The paper introduces a systematic design procedure of SRMs in a manner which is very similar to that used for the traditional machines. This design approach combines magnetic, graphical and relational parameters, in order to estimate the whole motor dimensions. Since, the geometrical parameters and the resulting change in the magnetic flux distribution are related analytically, it is therefore very simple to obtain a basic insight into the effect of various parameters on the magnetic field distribution without the need of many finite element analysis solutions. Finally, the proposed routine makes the design of the motor more popular to designers who are used to the design of conventional machines.

\section{REFERENCES}

[1] P. J. Lawrenson, J. M. Stephenson, J. Corda, and N.N. Fulton, Variable Speed Switched Reluctance Motors. IEE Proc., Vol. 127, Pt. B, No. 4, July (1980), pp. 253 265.

[2] M. Moallem, Chee-Mun Ong, and L. E. Unnewehr, "Effect Of Rotor Profiles on the torque of a Switched Reluctance Motor," IEEE Trans. on Ind. Appl., Vol. IA-28, No. 2, March/ April (1992), pp. 364 - 369.

[4] Arther V. Radun, "Design Consideration for the Switched Reluctance Motor," IEEE Trans. on Ind. Appl., Vol. IA-31, No. 5, September/ October (1995), pp. 1079 1087.

[5] M. M. Ahmed and M. A. EL-Khazendar, "Optimum Design of an Isolated Switched Reluctance Generator," AL-Azhar Engineering Fourth International Conference December 16 - 19, 1995, pp. 330 - 341.

[6] J. R. Suriano, and Chee-Mun Ong, "Variable Reluctance Motor Structures For Low Speed Operation," IEEE Trans. on Ind. Appl., Vol. IA-32, No. 2, March/ April 1996, pp. $345-353$.

[7] R. Krishnan, R. Arumugam, and J. F. Lindsay, "Design procedure for Switched Reluctance Motor," IEEE Trans. on Ind. Appl., Vol. IA-24, No. 3, May/ Junel (1988), pp. $456-461$.

[8] J. Faiz, and J. W. Finch, "Aspects of Design Optimization For Switched Reluctance Motors," IEEE Trans. on Energy Conversion, Vol. EC-8, No. 4, December (1993), pp. 704 - 713.

[9] N. N. Fulton, "The Application Of CAD to Switched Reluctance Drives, "Electric Machines and Drives Conference, London, UK. December (1987), IEE Conference Publication 282, pp. 275 - 279.

[10] T. J. E. Miller and M. McGilp, "PC CAD for Switched Reluctance Drives," Electric Machines and Drives Conference, London, UK. December 1987, IEE Conference Publication 282, pp. 360 - 366.

[11] Yifan Tang and Joseph A. Kline, Modeling and design optimization of Switched reluctance machine by Boundary element analysis and simulation, IEEE Trans. on Energy Conversion, Vol. 11, No.4, Dec. (1996), pp. 673: 680.

[12] Yifan Tang, Characterization, Numerical Analysis and Design of Switched Reluctance Motors, IEEE Trans. on Ind. Appl., Vol. IA-33, No. 6, Nov. /Dec. (1997), pp. 1544: 1552.

[13] Duane C. Hanselman, Brushless Permanent Magnet Motor Design, McGrawHill,Inc., (1994). 
Proceedings of the $2^{\text {nd }}$ ICEENG Conference, 23-25 Nov. 1999.

\begin{tabular}{|l|l|}
\hline EP-4 & 14 \\
\hline
\end{tabular}

[14] T. J. E. Miller, Switched Reluctance Motors and Their Control. Published jointly by Hillsboro, $\mathrm{OH}$ : Magna Physics Tridelta and London, UK: Oxford University Press, (1993).

[15] M. A. L. Badr, R. Mostafa, and A. S. El-Wakeel, "Switched reluctance Drive As Fault Tolerant Drive, "Proceeding of the 1st ICEENG conference, M.T.C., Egypt, 24 26 March, (1998).

[16] Austin Hughes, Electric Motors and Drives: Fundamentals, Types and Applications, second edition, Newnes, 1994.

[17] K. Backhaus, L. Link, and J. Reinert, "Investigation on a High Speed SRD incorporating Amorphous iron," EPE 95, Sevilla, (1995), pp. 460 - 464.

[18] M. R. Harris, A. Hughes, and P. J. Lawrenson, "Static Torque Production in saturated doubly salient machines," IEE Proc., Vol. 122, No. 10, October (1975), pp. $1121-1127$.

[19] M. R. Harris, V. Andjagholi, P. J. Lawrenșon, A. Hughes, and B. Ertan "Unifying Approach To the Static Torque of Stepping Motor Structures," IEE Proc., Vol. 124, No. 12, December (1977), pp. 1215 - 1224.

[20] H. C. J. DE Jong, A. C. Motor Design With Conventional And Converter Supply. Published by Oxford University Press, 1976, pp. 56 - 58.

[21]A. K. Sawhney, A course In Electrical Machine Design. Dhanpat Rai \& Sons, (1982). 